\title{
UN Office for Disaster Risk Reduction (2020)
}

\author{
Marie Aronsson-Storrier*
}

\section{Introduction}

In 2020, much of the world experienced a realisation of systemic risk. As the SARS-CoV-2 virus, known as COVID-19, spread across continents, including to states usually spared from "disasters", the importance of disaster risk reduction (DRR) measures grew clearer. Although the World Health Organization was at the head of the international response to the pandemic, it soon crystallised as a clear illustration of the complex and systemic nature of risk, ${ }^{1}$ which is an area in which the UN Office for DRR (UNDRR) has significant expertise. This allowed the agency to position itself as an increasingly important actor in the implementation of the wider Agenda $203 \mathrm{O}$.

Alongside publications and events relating to the pandemic, other trends in UNDRR's work were an increased focus on the adoption and implementation of national and local DRR strategies in accordance with Target E of the Sendai Framework for Disaster Risk Reduction $2015^{-2030},{ }^{2}$ as well as a turn towards ecology and nature-based risk reduction solutions.

\section{Status Report on Target E Implementation 2020}

In late 2O2O, the UNDRR published its Status Report on Target E Implementation 2020. ${ }^{3}$ There are two indicators developed by the Open-ended Intergovernmental Expert Working Group on Indicators and Terminology relating to Disaster Risk Reduction (OIEWG), namely: E-1: 'Number of countries that adopt and implement national disaster risk reduction strategies in line

* Lecturer, University of Reading.

1 As acknowledged by the UN Secretary General, the pandemic 'highlights the systemic nature of risk and the potential for cascading impacts across systems and borders'. See UNGA, Implementation of the Sendai Framework for Disaster Risk Reduction 2015-203o Report of the Secretary-General (23 July 2020) UN Doc. A/75/226, para 4.

2 Sendai Framework for Disaster Risk Reduction 2015-2030 (18 March 2015) UN Doc A/CONF.224/CRP.1. Adopted by the UNGA in Res 69/283 (23June 2015) UN Doc A/REs/69/283.

3 UNDRR, Status Report on target E implementation 2020 (UNDRR Status Report) <https:// www.undrr.org/publication/status-report-target-e-implementation-2020> last accessed (as any subsequent URL) on 3 June 2021. 
with the Sendai Framework for Disaster Risk Reduction 2015-2030'; and E-2: 'Percentage of local governments that adopt and implement local disaster risk reduction strategies in line with national strategies'. The Status Report presents progress made against both indicators between 2015 and 2019. It also identifies particular challenges in relation to the development of national and local DRR strategies and provides advice and techniques by which such challenges can be overcome. The report is based on the data from the Sendai Framework Monitor (SFM) as of 21 August 2020, and it is important to note that the SFM permits 'open-ended reporting', meaning that states can retroactively revise the submitted data later in time should they wish to do so. The Report uses all available data and includes self-reported data that has not yet been validated and, importantly, notes that the figures contained in it do not represent a complete picture of the ongoing work involved in developing national DRR strategies. ${ }^{4}$

In terms of progress, the UNDRR reported that 134 (out of 195) countries had engaged with the SFM. 93 countries reported that they have a National DRR strategy which is aligned with the SFDRR 'to some extent', with 44 reporting 'substantial or comprehensive alignment'. The UNDRR has established as a goal that this number will increase to 150 by the end of $2021 .{ }^{6}$ Out of the 93 countries with a National Strategy, 69 reported that they also have local strategies in place. The total number of countries reporting the existence of local DRR strategies is now 72 , an $85 \%$ increase since $2015 .{ }^{7}$

While significant progress has been made in relation to Target $\mathrm{E}$ over the past 5 years, it is clear that much work remains to be done in supporting states with the development and implementation of national and local DRR strategies. The UNDRR has also identified a need for further support for states in engaging with the SFM and sharing their progress. ${ }^{8}$

The inclusion of strategies defined as 'in line with the Sendai Framework for Disaster Risk Reduction 2015-2030' in E-1, demands a qualitative assessment of adopted strategies. Here, the UNDRR has developed 10 elements which

4 Ibid, 31.

5 Ibid, 16. Although leaving significant room for improvement, this is more than double the number (111\% increase) compared with 2015 .

6 Ibid, Annex 2. It should be noted that the Annex speaks of 'Sendai Framework-compliant DRR strategies' rather than alignment 'to some extent', which also suggests a qualitative improvement.

7 Ibid, 9 .

8 In particular, many Small Island Developing States which have relevant strategies in place, have not reported this in the SFM, which is of particular importance due to their significant vulnerability and exposure to hazards. Ibid, 20. 
should be included in such practices. ${ }^{9}$ The report provides a short overview of states' qualitative self-assessment against two of these elements, namely: (1) Promote policy coherence and compliance, notably with the SDGs and the Paris Agreement; and (2) Have mechanisms to follow-up, periodically assess and publicly report on progress.

As concerns the first, the report states that 85 countries reportedly had strategies promoting this coherence by $2019 .{ }^{10}$ This is a significant increase from 33 in 2015, but still demonstrates a need for further focus on this area." ${ }^{11}$ There are also uncertainties as to how this key element should be, and has been, interpreted by the reporting states, which should be kept in mind when reviewing these numbers.

Turning to the second key element, nearly all countries which reported that they have a national DRR strategy, also reported that they have mechanisms for follow-up, periodic assessment, and public report on progress (89). Again, a significant increase is seen since 2015 (up from 36$).{ }^{12}$ In terms of quality, the

9 UNDRR, Technical guidance for monitoring and reporting on progress in achieving the global targets of the Sendai Framework for Disaster Risk Reduction (2018) (UNDRR, 'Technical guidance') $115^{-116}$. The 10 elements are:

i. Have different timescales, with targets, indicators and time frames

ii. Have aims at preventing the creation of risk

iii. Have aims at reducing existing risk

iv. Have aims at strengthening economic, social, health and environmental resilience

v. Address the recommendations of Priority 1, Understanding disaster risk: Based on risk knowledge and assessments to identify risks at the local and national levels of the technical, financial and administrative disaster risk management capacity

vi. Address the recommendations of Priority 2, Strengthening disaster risk governance to manage disaster risk: Mainstream and integrate DRR within and across all sectors with defining roles and responsibilities

vii. Address the recommendations of Priority 3, Investing in disaster risk reduction for resilience: Guide to allocation of the necessary resources at all levels of administration for the development and the implementation of DRR strategies in all relevant sectors

viii. Address the recommendations of Priority 4, Enhancing disaster preparedness for effective response and to "Build Back Better" in recovery, rehabilitation and reconstruction: Strengthen disaster preparedness for response and integrate DRR response preparedness and development measures to make nations and communities resilient to disasters

ix. Promote policy coherence relevant to disaster risk reduction such as sustainable development, poverty eradication, and climate change, notably with the SDGs and the Paris Agreement

x. Have mechanisms to follow-up, periodically assess and publicly report on progress.

Ibid.

Ibid, 23 . 
report states that, on average, countries consider the effectiveness of measures according to this element of the Sendai Framework to be 'moderate. ${ }^{13}$

Most of the report is focused on Target E1, but it also discusses progress made in accordance with Target E2. Here, the picture is a rather mixed one. On the one hand, while the number of countries reporting that they have adopted a local strategy has increased, the proportion of local governments with a DRR strategy within the reporting countries has fallen slightly since 2015. Although the reasons for this are unclear, the call from the UNDRR leaves little room for doubt: 'all countries are recommended to strengthen DRR governance at the local level'.

\section{$3 \quad$ Words into Action Guidelines}

The UNDRR has published a series of Words into Action (WiA) guidelines since the adoption of the Sendai Framework. The guidelines are aimed at aiding and strengthening the implementation of the Sendai Framework and are produced through knowledge co-production in order to draw on diverse 'sources of know-how'. In 2020, the UNDRR published the WiA guidelines 'Implementation guide for local disaster risk reduction and resilience strategies' and 'Enhancing disaster preparedness for effective response', as well as the draft for public review of the WiA guideline on 'Nature-based solutions for disaster risk reduction'.

\subsection{Implementation Guide for Local Disaster Risk Reduction and Resilience Strategies}

The Implementation guide for local disaster risk reduction and resilience strategies ${ }^{14}$ presents numerous examples of good practice from around the world, and particularly stresses the importance that national strategies should be based on an inclusive whole-of-society approach and aimed at 'preventing the creation of new disaster risk', 'reducing existing disaster risk', and 'strengthening economic, social, health, and environmental resilience. ${ }^{15}$

The guideline echoes the 2018 'Technical guidance for monitoring and reporting on progress in achieving the global targets of the Sendai Framework for Disaster Risk Reduction' in terms of the 10 key elements to be included

\footnotetext{
13 Ibid, 24.

14 UNDRR, Words into Action: Implementation guide for local disaster risk reduction and resilience strategies $(2 \mathrm{O} 20)$.

15 Ibid, 12.
} 
in a national strategy, ${ }^{16}$ and also sets out a 10-step approach to developing a national disaster risk reduction strategy divided into three phases (I. building understanding and evidence; II. Designing the strategy and action plan; III. Preparing for implementation):

1. Understand the DRR country context: conduct a preliminary assessment and stocktaking of the existing disaster risk reduction system

2. Define the high-level objectives and vision of the DRR strategy

3. Define the most appropriate multi-sectoral institutional mechanism to lead the development of the national DRR strategy

4. Evaluate the availability of financial resources - engage in dialogue with Ministry of Finance

5. Design the work plan for developing the national DRR strategy

6. Publicly communicate and reach out on the process of developing the national DRR strategy

7. Consolidate evidence into a draft strategy

8. Secure and activate funding sources for implementation

9. Mobilize partnerships for country-level implementation

10. Set up a monitoring, evaluation and reporting mechanism linked to the national strategy implementation

Key themes throughout the WiA include highlighting the importance of an inclusive multi-hazard, all of society approach, enhancing coherence between DRR, CCA and the wider Agenda 2030, as well as between local and national level efforts, and developing implementing national strategies for DRR.

\subsection{Enhancing Disaster Preparedness for Effective Response}

As suggested by its title, this WiA guideline ${ }^{17}$ is focused on SFDRR priority 4 and seeks to support the improvement of disaster preparedness for effective response. It takes a multi-sector and multi-level approach and is aimed at actors working to strengthen risk-informed disaster preparedness within a country. The guideline makes extensive reference to existing, more detailed, resources for different stakeholders, and also provides helpful examples of preparedness measures..$^{18}$

16 UNDRR, Technical guidance (n 9) 115-116, (see n 9 above).

17 UNDRR, 'Words into Action: Enhancing disaster preparedness for effective response' (2020) available at <www.preventionweb.net/files/53347_capstone.pdf $>$.

18 For examples of good practice, see, in particular, section 3 (32 ff.). 


\subsection{Nature-Based Solutions for Disaster Risk Reduction}

The public review version of the WiA guideline on Nature-based solutions for disaster risk reduction ${ }^{19}$ was published by the UNDRR in October 2020 and was open for public review until 12 January 2021. The document demonstrates a clear and growing acknowledgement of the importance of protecting nature (as opposed to simply preventing and preparing for damage caused by forces of nature) as a fundamental aspect of DRR. Specifically, it seeks to provide practical guidance as to how to establish nature-based solutions for DRR, as well as for CCA. Acknowledging not only the detrimental effect of disasters on the environment, but also the role of environmental degradation in causing hazards, it highlights the importance of environmental management, including land management and the sustainable use and management of ecosystems protection in disaster risk reduction.

This guideline is part of a wider effort to promote nature-based solutions for DRR and could be read together with the UNDRR's 'Ecosystem-Based Disaster Risk Reduction Implementing Nature-based Solutions for Resilience.'20

\section{Other Publications and Events}

UNDRR published a large number of reports and guidance documents during 2020 , including the Action brief aimed at the advancement of gender-responsive DRR in the context of COVID-19, ${ }^{21}$ and the report 'Human Cost of Disasters: An overview of the last 20 years 2000-2019' (together with the Centre for Research on the Epidemiology of Disasters). ${ }^{22}$ Readers of this journal will be particularly interested in the commentaries highlighting the importance of

19 UNDRR, Words into Action: Nature-based solutions for disaster risk reduction (draft for public review) (2020) available at <https://www.preventionweb.net/publications/ view/74082>.

20 UNDRR, Ecosystem-Based Disaster Risk Reduction Implementing Nature-based Solutions for Resilience (2020), available at <https://www.undrr.org/publication/ecosystem-based -disaster-risk-reduction-implementing-nature-based-solutions-o>. UNDRR, Action brief aimed at the advancement of gender-responsive DRR in the context of covid-19 (2020) available at <https://www.preventionweb.net/publications/view/ $75410>$.

22 Centre for Research on the Epidemiology of Disasters and UNDRR, 'Human Cost of Disasters: An overview of the last 20 years 2000-2019' (2020), available at $<$ https://www .undrr.org/sites/default/files/inline-files/Human\%2oCost\%20of\%2oDisasters\%2O200o $-2019 \%$ 2OFINAL.pdf>. 
the Sendai Framework in relation to the pandemic, and how the pandemic is a manifestation of systemic risk..$^{23}$

With the COVID-19 pandemic generally preventing large scale in-person gatherings from taking place in $2020,{ }^{24}$ the restrictions on travel did open for opportunities of bringing people together in virtual meetings and webinars in a way that has not been previously utilised. The UNDRR and its regional offices organised a number of webinars throughout the year, with the majority of them focusing on how to move through and forward from the CoviD-19 pandemic, and the interaction and integration between different risks and areas of governance. ${ }^{25}$

The many disasters triggered by storms, floods, and landslides in the midst of the ongoing COVID-19 pandemics in $2020,{ }^{26}$ reminds us of the importance of the DRR perspective within the broader Agenda 2030 framework. Often forgotten by those working in the 'humanitarian and development nexus, ${ }^{27}$ the UNDRR plays a central part in promoting, implementing, and furthering the understanding of DRR, and provides us not only with productive tools, but also helpful conceptualisations of some of the most pressing global challenges of our time.

23 On Covid-19 and the Sendai Framework, see Marco Toscano-Rivalta, 'Disaster risk reduction in light of the COVID-19 crisis: Policy and legal considerations', Questions of International Law (Zoom Out) (19 June 2020), available at <http://www.qil-qdi.org/ disaster-risk-reduction-in-light-of-the-covid-19-crisis-policy-and-legal-considerations/>. In addition, Marc Gordon and Scott Williams published a series of eight short pieces on COvid-19 and systemic risk in April 2020. The articles are available at $<$ https://www .preventionweb.net/collections/covid19-systemicrisk>.

24 Information about all the events that UNDRR organised in 2020 can be found at $<$ https:// www.undrr.org/news-events/event-calendar>.

25 See, ibid.

26 See, e.g., Centre for Research on the Epidemiology of Disasters, 2020 Annual Report (2021) available at $<$ https://www.emdat.be/publications $>$.

27 John H. Patterson and Topher L. McDougal, 'Revenge of the nerds: Disaster risk reduction and climate change', The New Humanitarian (18 March 2021), available at <https://www .thenewhumanitarian.org/opinion/2021/3/18/revenge-of-the-nerds-disaster-risk-reduc tion-and-climate-change>. 